between these two motivations, but on the whole it has been a creative tension. Academic psychologists have certainly benefited from the insights and experiences of people with clinical experience.

In this country, the enterprising and highly successful Journal of Child Psychology and Psychiatry has played an important part in making this contact between academic researchers and practitioners possible. For many years this journal has published scientific papers of a high standard, which usually interest people with clinical interests as well as academic readers.

Now the association that runs this journal has started a new enterprise: the Child Psychology and Psychiatry Review. Its purpose is to keep practitioners informed about the latest developments in research and in practice, and it sets out to do so in several ways. Each issue contains commissioned articles or sets of commissioned articles that provide up-to-date and highly readable reviews of a particular topic (for example, dyslexia, behavioural genetics). It also contains submitted articles and a journal monitor section with brief summaries of papers in other journals that are relevant to particular childhood problems, such as child abuse and educational difficulties. Most issues also have a section on legal matters. There is an occasional personal profile, each with an interview of a well-known child psychologist or psychiatrist. The new journal also contains a fairly lively correspondence section.

The articles are a mix of down-to-earth accounts of clinical practice and of up-to-date descriptions of theories on this or that aspect of childhood. They are all written clearly and with an attractive simplicity. The other sections of the journal are also interesting and informative, except for the personal profile section which has a parochial air and does not seem to me to add any stimulating new information. Apart from this, the editors of this new journal are providing busy practitioners with an entertaining but intellectually respectable account of current research. Peter Bryant is in the Department of Experimental Psychology, University of Oxford, South Parks Road, Oxford OX1 3UD, UK.

\section{The chaotic psyche}

\section{Nonlinear Dynamics, Psychology, and Life Sciences \\ Editor Stephen J. Guastello \\ Human Sciences Press. 4/yr. USA \$110, \\ elsewhere $\$ 130$ (institutional); USA \$35, elsewhere $\$ 41$ (personal)}

\section{H.Eugene Stanley}

The emerging field of nonlinear science has led to many advances and to many new journals - Fractals, Nonlinearity and Physica D to name just three. Recently, the concepts and methods of nonlinear science have also been finding interesting applications in the social sciences. Witness, for example, the popularity of applying methods of statistical physics to problems of economics and finance, an endeavour that has spawned many interesting ideas and topical conferences in Budapest, Palermo and Dublin under the rubric of 'econophysics'.

Other topics in the social sciences that appear to be amenable to the concepts and methods of statistical physics include problems associated with urban growth, where one quantitatively analyses the locations of homes, or foraging phenomena, where one asks for the most efficient strategy to find an object (food or lost car keys).

In all this work, there is no attempt to model the free will of the subject that determines the outcome, be they a Wall Street trader, a citizen building a home, or the foraging birds and bees. Presumably individuals do not exercise their free will, but learn efficient strategies and implement them.

In the fields of psychology and psychoanalysis it is hard to deny the role of free will, hence a journal devoted to the applications of concepts of nonlinear science to these disciplines would seem most interesting. The papers collected in the first issues span a range of problems of general interest in psychology, and bring to bear on them concepts such as catastrophe theory and fractal theory. Out of these marriages arise children with unfamiliar names such as 'collective intelligence' and 'stochastic determinism' (an oxymoron at first sight).

Will this moderately priced journal fulfil the need for a genuinely interdisciplinary journal on nonlinear science applied to the social sciences? It seems doubtful. The editorial board contains no physical scientists or practitioners of statistical mechanics, the discipline most active in nonlinear science. Further, there is a strong emphasis on psychology rather than on a wider range of social sciences. Moreover, if the initial issues are any guide, there is a tendency in many of the papers to simply 'talk' rather than report new experiments, simulations or scientific

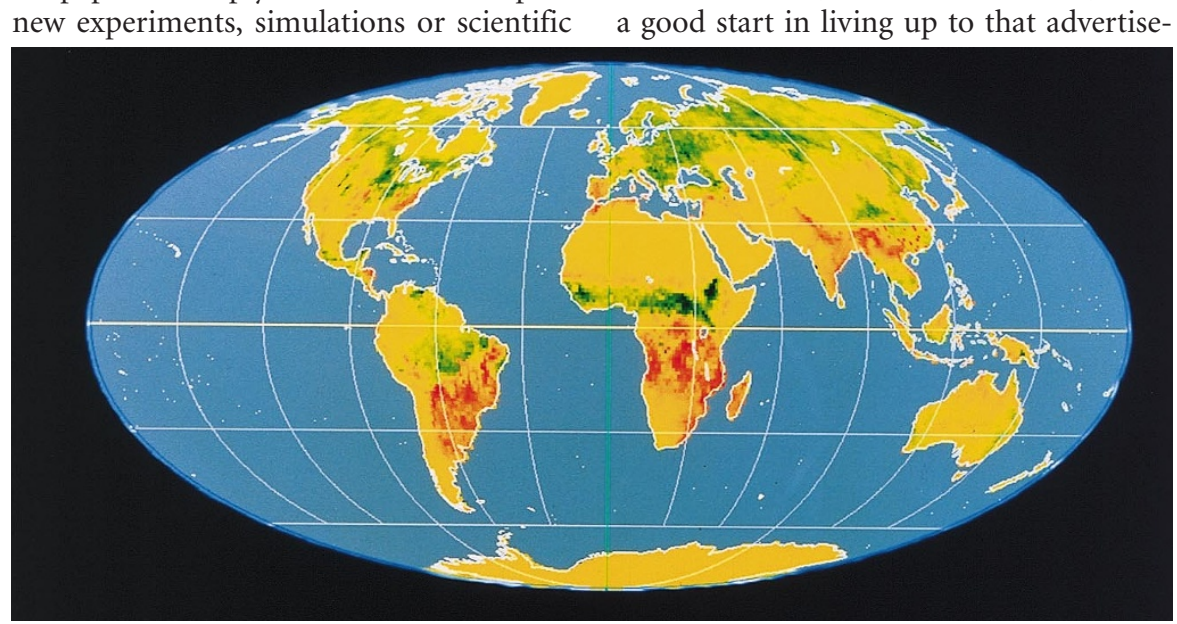

The fixing of $\mathrm{CO}_{2}$ (green) and its release through plant decomposition (red) in a typical June. models. There are even a few misunderstandings of some of the principles of nonlinear science.

These limitations might be overcome, and the journal fulfil its potential, if it were to broaden its horizons and undertake rigorous refereeing procedures.

H. E. Stanley is at the Center for Polymer Science, Boston University, 147 Bay State Road, Boston, MA 02215, USA.

\section{No waste of trees}

\section{Boreal Environmental Research}

Editors-in-chief Hannu Lehtonen and

Sylvain Joffre

Finnish Zoological and Botanical Publishing Board. 4/yr. FM500, \$100 (institutional);

FM200, $\$ 40$ (personal)

\section{David W.Schindler}

No single ecological type, or 'biome', covers more first-world countries than the Boreal, with forests that extend over most northerly latitudes of Eurasia and North America, including Scandinavia, the former Soviet Union, Canada, and the northern USA. For the past 30 years, residents and environmental organizations of these countries have expressed their displeasure at the rapid exploitation of tropical forests, not noticing that boreal ecosystems under their very noses were quietly being sacked at an equally astounding rate. The boreal zone also contains more than 90 per cent of the world's lakes. Its vast wetlands are pivotal ecosystems in greenhouse gas balances.

In the past, research on boreal lands and waters has been diffused through a number of more general ecological publications, making it difficult to find. A journal that advertises itself as devoted to boreal science in the broadest sense, emphasizing holistic approaches to boreal problems by experimental, monitoring, theoretical and modelling approaches, is therefore long overdue.

Volumes one and two of Boreal Environmental Research, from 1996 and 1997, make a good start in living up to that advertise-

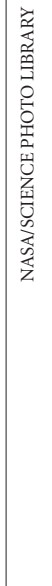


ment. Research on lakes, streams, wetlands, forests and the Baltic Sea is included. While most of the papers are by Finnish scientists, there are a fair number from Norway and Sweden and a sprinkling from Canada, China and other countries. The quality of research papers is comparable with those published in well-known ecological periodicals from other countries. I am confident that as the journal becomes more widely known, the authorship will become more broadly international. That being said, a journal that makes the excellent, but often quite inaccessible, boreal research in Finland easily available internationally is important in its own right.

The journal is remarkably well turned out for a new, modestly priced periodical. Figures and tables are clear and well reproduced, and the layout is very attractive. In contrast to many foreign-produced publications in English, the writing and editing is nearly flawless ... in fact, better than in most English language publications from North America.

My sole criticism is that several of the papers do not reference key relevant research papers from North America. This would easily be corrected by using referees from more countries, which will no doubt happen as the journal attracts a more international authorship. Publication is very rapid, on average about four months after acceptance for the volumes under review.

Perhaps my highest recommendation is that I have recommended that our library subscribe, despite declining budgets for journals. It is indispensable for those working in the Boreal, and very useful for those engaged in ecological research in other ecosystems.

David W. Schindler is in the Department of Biological Sciences, University of Alberta,

Edmonton T6G 2E9, Canada.

\section{Common ground among quagmires}

\section{Journal of Industrial Ecology}

Editors David Allen and John Ehrenfeld MIT Press. 4/yr. \$95 (institutional); \$40 (personal)

\section{GilbertS. Hedstrom}

The business world of the twenty-first century is likely to be shaped by now-familiar forces, including rapid technology development, greater openness and vitality in political systems, and rampant globalization. At the same time, a second set of forces has the power to strongly affect the direction it takes. These 'sustainability drivers', fuelled by increasing world population and declining living systems, may be the least appreciated, least understood set of threats and opportu- nities facing business.

Industrial ecology is a discipline that provides for exploring this territory and exploiting this new set of opportunities. While the term 'industrial ecology' has been around for over ten years, this is essentially a new field. And like any new field, it has the potential for either bringing clarity and focus to significant issues or becoming mired in jargon and academic debate. For industrial ecology to be a useful part of sustainability solutions, the scientific, government and business communities will need to speak the same language, based not on self-interest and emotion but rather on common interests and logic.

The Journal of Industrial Ecology takes a major step in bringing clarity to a potentially very confusing topic. The quarterly journal, launched in the winter of 1997, offers a thoughtful and comprehensive, yet accessible venue for exploring the potential role of industry and government in reducing the environmental burdens throughout the product life cycle, from extraction of raw materials, to the production of goods, to the use of those goods and to the management of the resulting wastes.

Several factors distinguish this journal. It is timely, for to think about issues of sustainability as the next century dawns is both prudent and ethical. Its global perspective brings fresh and balanced voices to a sometimes parochial discussion. Finally, it is both very readable and very well edited, with the articles fitting together more like a puzzle than a melange of individual contributions.

Not to be read only once or in one sitting, this journal is an important reference for those interested in how business and government can maintain the benefits of the first industrial revolution while dramatically reducing the burden those benefits place on the underlying living systems that need to be sustained during the next industrial revolution.

Gilbert S. Hedstrom is at Arthur D. Little, Inc., Acorn Park, Cambridge, Massachusetts 02140, USA.

\section{Imperilled wetlands}

\section{Mangroves and Saltmarshes}

Chief Editors Eric Wolanski and Charles S. Hopkinson Jr.

SPB Academic Publishing. 4/yr. Print only. $\$ 152$ (institutional); $\$ 80$ (personal)

\section{Thomas J.Smith III}

Mangrove forests dominate the intertidal zone of the world's tropical coastlines, yielding to saltmarshes in the temperate and arctic zones. Unfortunately, more than 80 per cent of the world's population also lives in the coastal zone. Saltmarshes and mangroves face tremendous human pressure from

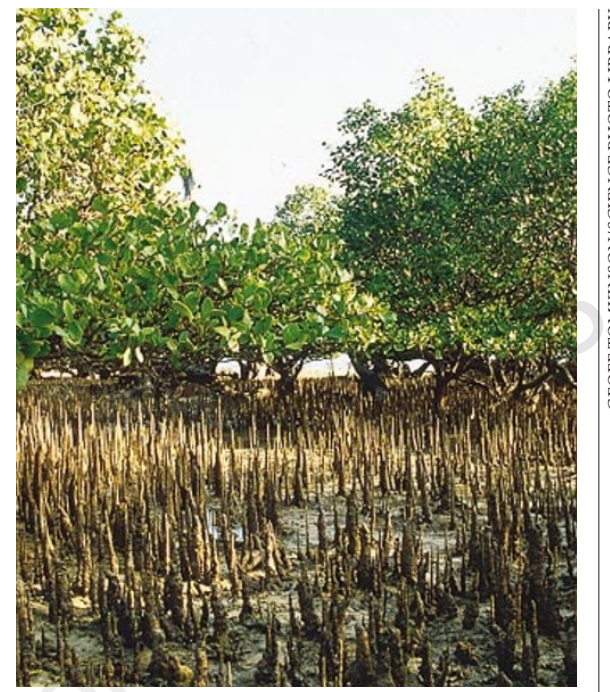

Coastal mangrove swamp at low tide.

development, despite their known ecological services to man. These services include: supporting productive fisheries; preventing shoreline erosion, especially from storms; and the uptake and transformation of nutrients. In some developing countries in the tropics, mangrove forest is being lost at a rate of more than 10 per cent a year. A journal devoted to the scientific understanding and enlightened management of these two important coastal ecosystems is therefore quite justifiable.

Since its launch in December 1996, Mangroves and Saltmarshes has published four issues, each with six research articles. Papers address both pure and applied research topics, but notes, comments, rebuttals, book reviews and so on are not included. The layout and graphical presentation are very good, and the turnaround time for submissions is quick. Based on the dates presented in the last two issues, the average paper takes four to five months from submission to acceptance.

Unfortunately, the quality of the papers in the issues I reviewed was highly variable; ranging from horrid (presumably on the principle that if a paper has been rejected everywhere else, send it to a new journal) to truly excellent. The quality is not related to the country of origin; indeed, the worst paper, in my opinion, was from a member of the editorial board.

A strength of the journal is that the editorial board is endeavouring to assist authors from less developed nations to present their results to the worldwide scientific community.

Many paradigms concerning mangrove forests were originally developed from studies in Florida, but these paradigms do not necessarily hold for mangroves worldwide. So the presentation of research conducted in the vast expanses of mangroves in less developed areas is needed. Authors from the developed world need to see these studies 